\title{
Phenotypic Tfh development promoted by CXCR5-controlled re-localization and IL-6 from radiation-resistant cells
}

\author{
Xin Chen ${ }^{1,2 \bowtie}$, Weiwei $\mathrm{Ma}^{1,2}$, Tingxin Zhang ${ }^{1}$, Longyan $\mathrm{Wu}^{1,2}$, Hai $\mathrm{Qi}^{1,2 \bowtie}$ \\ 1 Tsinghua-Peking Center for Life Sciences, Tsinghua University, Beijing 100084, China \\ ${ }^{2}$ Laboratory of Dynamic Immunobiology, Institute for Immunology, School of Medicine, Tsinghua University, \\ Beijing 100084, China \\ $\bowtie$ Correspondence: xin.chen01@foxmail.com (X. Chen), qihai@tsinghua.edu.cn (H. Qi)
}

\begin{abstract}
How follicular T-helper (Tfh) cells develop is incompletely understood. We find that, upon antigen exposure in vivo, both naïve and antigen-experienced $\mathrm{T}$ cells sequentially upregulate CXCR5 and Bcl6 within the first $24 \mathrm{~h}$, relocate to the T-B border, and give rise to phenotypic $\mathrm{BCI}^{+}{ }^{\mathrm{CXCR}} 5^{+}$Tfh cells before the first cell division. CXCR5 upregulation is more dependent on ICOS costimulation than that of $\mathrm{Bcl}$, and early Bcl6 induction requires T-cell expression of CXCR5 and, presumably, relocation toward the follicle. This early and rapid upregulation of CXCR5 and BcI6 depends on IL-6 produced by radiation-resistant cells. These results suggest that a Bcl6 ${ }^{\text {hi }} \mathrm{CXCR}^{\text {hi }}$ phenotype does not automatically define a Tfh lineage but might reflect a state of antigen exposure and non-commitment to terminal effector fates and that niches in the T-B border and/or the follicle are important for optimal Bcl6 induction and maintenance.
\end{abstract}

KEYWORDS Tfh, CXCR5, Bcl6, radiation-resistant cell, IL-6

\section{INTRODUCTION}

Tfh cells are functionally distinguished by their ability to deliver contact-dependent help to $B$ cells inside the follicle

Xin Chen and Weiwei Ma have contributed equally to this work.

Electronic supplementary material The online version of this article (doi:10.1007/s13238-015-0210-0) contains supplementary material, which is available to authorized users.
(Crotty, 2011; Vinuesa and Cyster, 2011). Intrinsic T-cell expression of the transcriptional repressor $\mathrm{Bcl} 6$ is required for Tfh development and for germinal center (GC) formation (Johnston et al., 2009; Nurieva et al., 2009; Yu et al., 2009). How Bcl6 regulates Tfh development is not yet clear (Qi et al., 2014). One proposal is that Bcl6 drives CXCR5 upregulation, which subsequently promotes follicular localization of activated T cells. Consistent with this idea, Bcl6 overexpression in $T$ cells in vitro downregulates multiple microRNA species such as the mir-17 92 cluster that potentially suppress CXCR5 expression, leading to increased CXCR5 transcript levels (Yu et al., 2009). However, genetic ablation of mir-17 92 impairs rather than promotes Tfh development and GC formation (Baumjohann et al., 2013; Kang et al., 2013). No evidence yet indicates direct Bcl6-mediated regulation of Cxcr5 gene expression, and Bcl6-deficient $T$ cells can upregulate CXCR5 under certain conditions (Liu et al., 2012), whereas the transcription factor Achaete-Scute homologue 2 (Ascl-2) directly binds to the $\mathrm{CxCr} 5$ locus and triggers CXCR5 upregulation (Liu et al., 2014). An alternative scenario is that Bcl6 drives a comprehensive Tfh developmental program of which CXCR5 upregulation is a manifestation (Crotty, 2014; Hatzi et al., 2015; Ueno et al., 2015). Consistent with this, T cells activated for 2 to 4 days in vivo are typically found to express Bcl6, likely under the influence of IL-6 (Nurieva et al., 2008; Harker et al., 2011; Choi et al., 2013), IL-12 (Ma et al., 2009; Schmitt et al., 2009; Nakayamada et al., 2011) and ICOS (Choi et al., 2011), while CXCR5 ${ }^{+} \mathrm{T}$ cells apparently only appear at later time points (Choi et al., 2011; Kerfoot et al., 2011; Kitano et al., 2011). Bcl6 ${ }^{+} \mathrm{CXCR}^{+}$cells are located at the T-B border (Kerfoot et al., 2011; Kitano et al., 2011) and require $\mathrm{DC}$ - but not $\mathrm{B}$ cell-mediated antigen presentation 
(Deenick et al., 2010; Choi et al., 2011; Goenka et al., 2011; Kerfoot et al., 2011). In a kinetic study, dividing T cells were found to express high levels of Bcl6 2 days after immunization, while they did not express CXCR5 until approximately one day later (Baumjohann et al., 2011). Therefore, the Tfh developmental program is thought to follow a typical Th effector differentiation paradigm in that accessory signals delivered by DCs drives expression of fate-determining transcription factors, which then orchestrate epigenetically inheritable lineage commitment through successive cell cycles (Zhu et al., 2010; Crotty, 2011). However, here we have examined the earliest kinetics of CXCR5 and Bcl6 expression by $\mathrm{T}$ cells activated in vivo and surprisingly found that $\mathrm{T}$ cells with a $\mathrm{Bcl} 6^{\text {hi }} \mathrm{CXCR} 5^{\text {hi }}$ phenotype arise before the first cell cycle and that CXCR5 is required for optimal Bcl6 upregulation.

\section{RESULTS}

The rapid appearance of phenotypic Tfh cells before cell divisions in vivo

To explore the earliest time point that T cells upregulate $\mathrm{Bcl} 6$, CXCR5 and acquire a Tfh phenotype following antigen activation in vivo, we examined OVA-specific OT-II CD4 ${ }^{+} \mathrm{T}$ cells in adoptive hosts at different time points after OVA immunization. As shown in Fig. $1 \mathrm{~A}$, by $12 \mathrm{~h}$ post immunization, OT-II T cells significantly upregulated CXCR5, while increase in $\mathrm{Bcl} 6$ expression was still minimal. PD-1 upregulation followed a similar kinetics as CXCR5. By 24 h, Bcl6 upregulation became evident, giving rise to an overt $\mathrm{Bcl6}^{\text {hi }} \mathrm{CXCR} 5^{\text {hi }}$ population (Fig. $1 \mathrm{~A}$ and $1 \mathrm{~B}$ ), even though virtually none of these cells divided (Fig. 1C). This rapid appearance of Tfh-like cells was not a recall response of memory cells potentially contaminating our $\mathrm{T}$ cell preparation, because CXCR5 and Bcl6 upregulation were also evident by $24 \mathrm{~h}$ when $\mathrm{CD} 4^{+} \mathrm{CD} 25^{-} \mathrm{CD} 6 \mathrm{~L}^{\text {high }} \mathrm{CD} 44^{\text {low }}$ OT-II T cells were tested (Fig. 1D). It was not a peculiar behavior of naïve T cells, because OT-II T cells that were first activated in vitro also rapidly and sequentially upregulated CXCR5 and Bcl6 in vivo with an essentially identical kinetics after OVA immunization (Fig. S1). Together, these data suggest that CXCR5 and Bcl6 upregulation may be a stereotypic behavior of $T$ cells responding to antigenic stimulation in vivo and that the appearance of a Bcl $6^{\text {hi }} \mathrm{CXCR} 5^{\text {hi }}$ Tfh phenotype per se could simply reflect acute antigenic activation rather than a differentiation program.

\section{Contribution of ICOS, CD40L and SAP signaling in early CXCR5 and Bcl6 upregulation}

It is well established that, by regulating T-B cell interactions and $T$ cell-intrinsic signaling properties, ICOS, CD40L, and SAP are critical for Tfh development and GC formation (Crotty, 2011). To test whether ICOS, CD40L or SAP has a role in this rapid and early induction of the Tfh phenotype, we analyzed $\mathrm{IcOS}^{-/-}, \mathrm{Cd}_{40 \mathrm{O}^{-/-}}$and $\mathrm{Sap}^{-/-}$OT-II T cells in adoptive B6 hosts. As shown in Fig. 2A and 2B, normal CXCR5 upregulation required ICOS but not CD40L or SAP. Strikingly, early $\mathrm{Bcl} 6$ upregulation did not require any of these molecules. ICOS co-stimulation enhances calcium signaling and PI3K activation (Parry et al., 2003; Gigoux et al., 2009), with the Tec family kinase ITK serving as one intermediate (Berg et al., 2005; Nurieva et al., 2007). Consistent with the differential effect of ICOS on CXCR5 and Bcl6 upregulation, enforced ITK over-expression on $T$ cells significantly enhanced early CXCR5 upregulation but had no effect on Bcl6 expression (Fig. 2C, 2D and 2E). Therefore, early CXCR5 and Bcl6 upregulation is a result of T cell receptor signaling and costimulation but not likely coupled in a simple regulatory circuit within T cells. CXCR5 upregulation is more sensitive to deprivation of ICOS co-stimulation than that of Bcl6.

\section{Early CXCR5 and Bcl6 expression correlate with T cell re-localization to the T-B border}

Although results presented above imply a stereotypic CXCR5 and Bcl6 upregulation following antigenic activation, it is important to note that mouse T cells activated in vitro, either by a combination of anti-CD3 and anti-CD28 stimulation or by antigen-pulsed dendritic cells or B cells, do not upregulate CXCR5 or Bcl6 with such kinetics (our unpublished data). These latter results suggest the importance of tissue microenvironment in vivo in permitting the rapid, antigen-triggered CXCR5 and Bcl6 upregulation. The fact that CXCR5 expression precedes overt $\mathrm{Bcl} 6$ induction raises the interesting question as to whether CXCR5-controlled T cell positioning in the tissue influences Bcl6 expression. As shown in Fig. $3 A$ and $3 B$, within the first $7 \mathrm{~h}$ post immunization, OT-II T cells were uniformly distributed in the T cell zone. By $24 \mathrm{~h}$, however, many OT-II T cells migrated to the T-B border and some were already inside the follicle. Such repositioning required CXCR5 upregulation, as $\mathrm{CxCr5^{-/- }}$ OT-II T cells failed to do so (Fig. 3C and 3D). Interestingly, these Cxcr5 ${ }^{-1-}$ OT-II T cells also failed to upregulate Bcl6 normally (Fig. 3E). Together, these data suggest environmental factors in the follicle or at the T-B border might positively promote Bcl6 expression.

\section{Early CXCR5 and Bcl6 expression are dependent} on radiation-resistant cell derived IL-6

IL-6 promotes Tfh cell development and germinal center reaction in vivo (Nurieva et al., 2008; Wu et al., 2009), with DC-derived IL-6 believed to be primarily responsible (Harker et al., 2011; Vinuesa and Cyster, 2011; Choi et al., 2013). Consistent with the importance of IL-6, the rapid upregulation of CXCR5 and Bcl6 was impaired when OT-II cells were activated in $/ 1-6^{-/-}$recipients (Fig. 4A). We further constructed mixed bone-marrow (BM) chimera using wildtype or $11-6^{-/-}$ donors and recipients. Interestingly, OT-II cells normally 
A
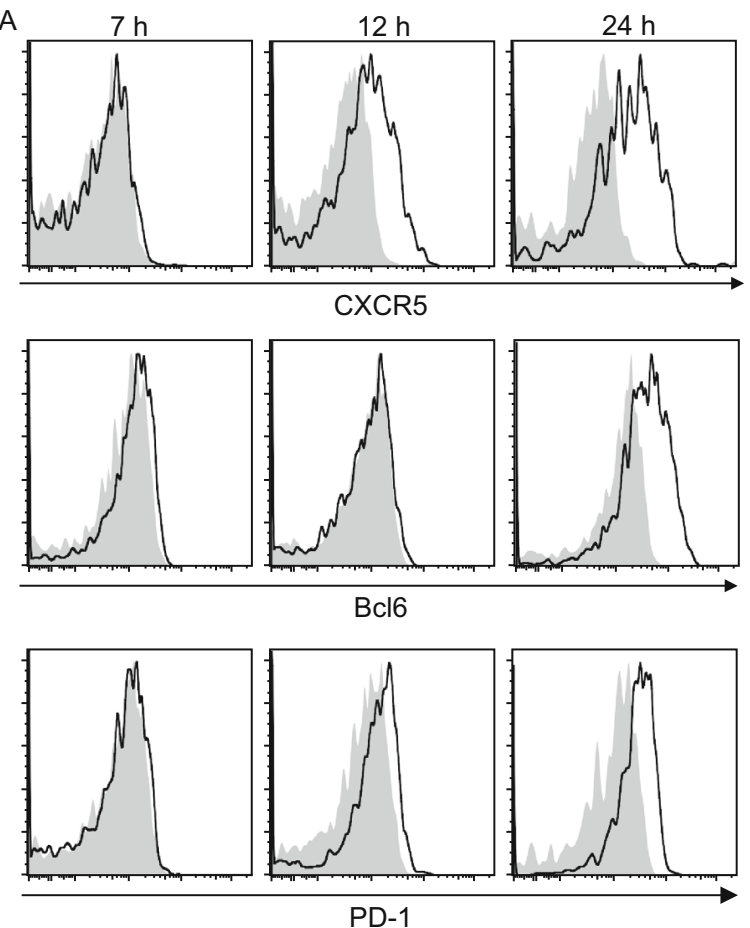

PD-1

B

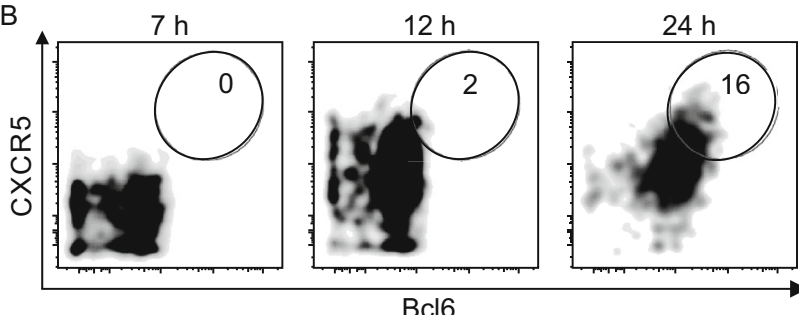

D
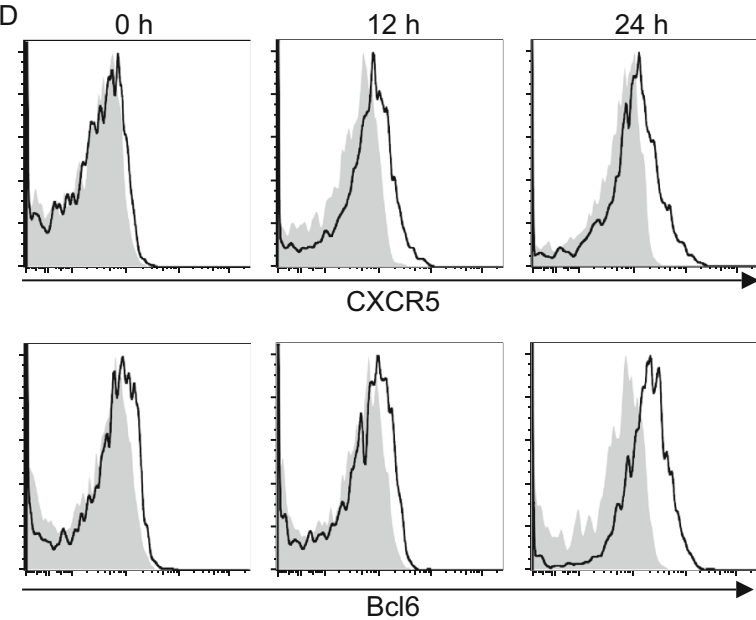
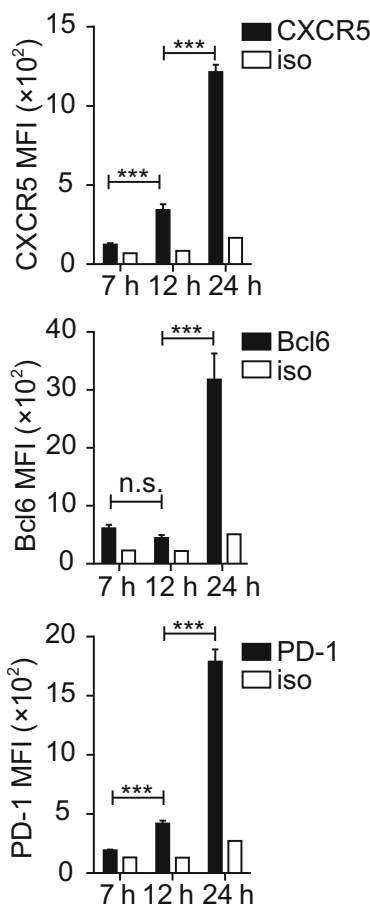

C
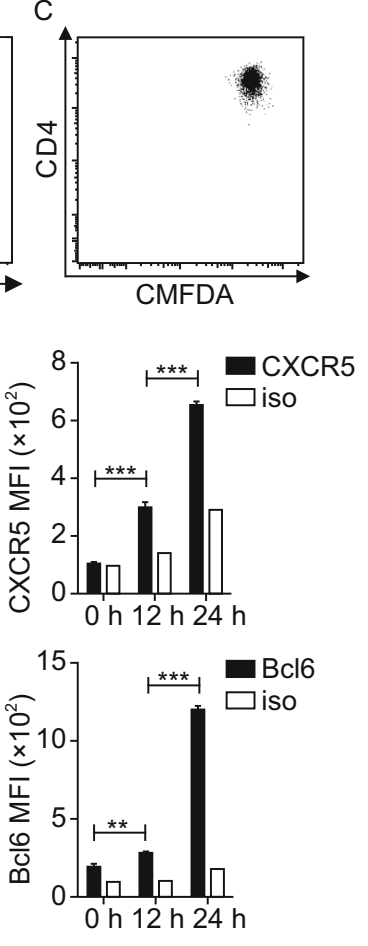

Figure 1. BCL6 ${ }^{\text {hi }} C X C R 5^{\text {hi }} T$ cells emerge before the first division following activation in vivo. (A) Representative histograms and absolute MFI values of CXCR5, Bcl6, and PD-1 or corresponding isotype staining of CMFDA-labeled OT-II T cells at indicated times after OVA/alum/LPS immunization. (B) Representative bivariate displays of Bcl6 and CXCR5 staining patterns. (C) Representative CMFDA profile of OT-II T cells $24 \mathrm{~h}$ post immunization. (D) CXCR5, Bcl6, and PD-1 expression by

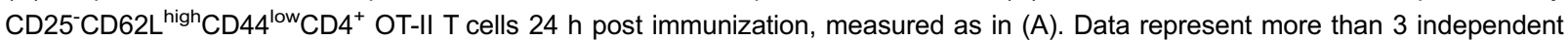
experiments (3-4 mice per group). ${ }^{* *} P<0.01 ;{ }^{* * *} P<0.001$; n.s., not significant. 
A
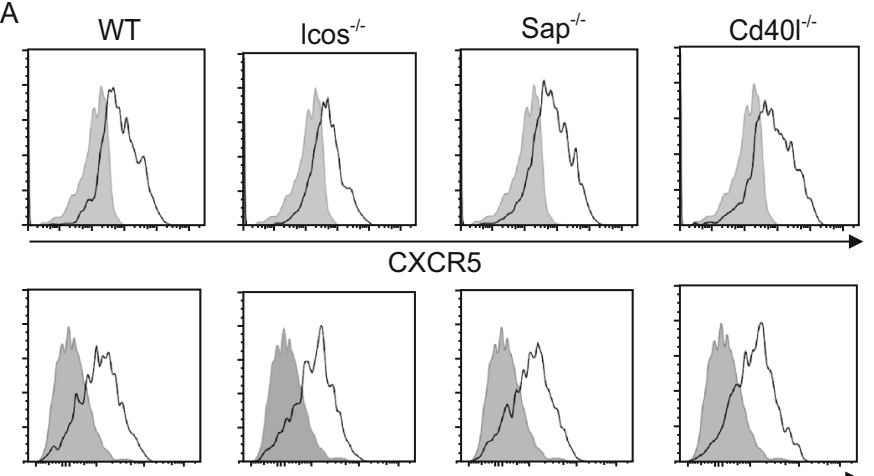

Bcl6

C

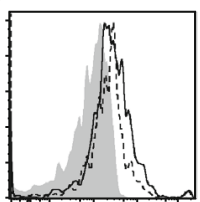

CXCR5

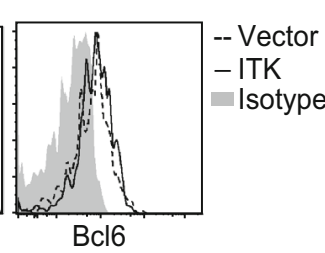

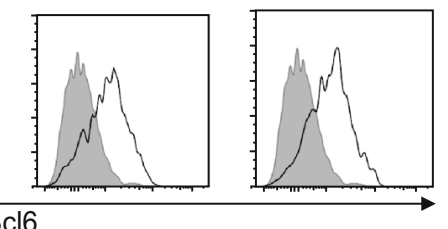
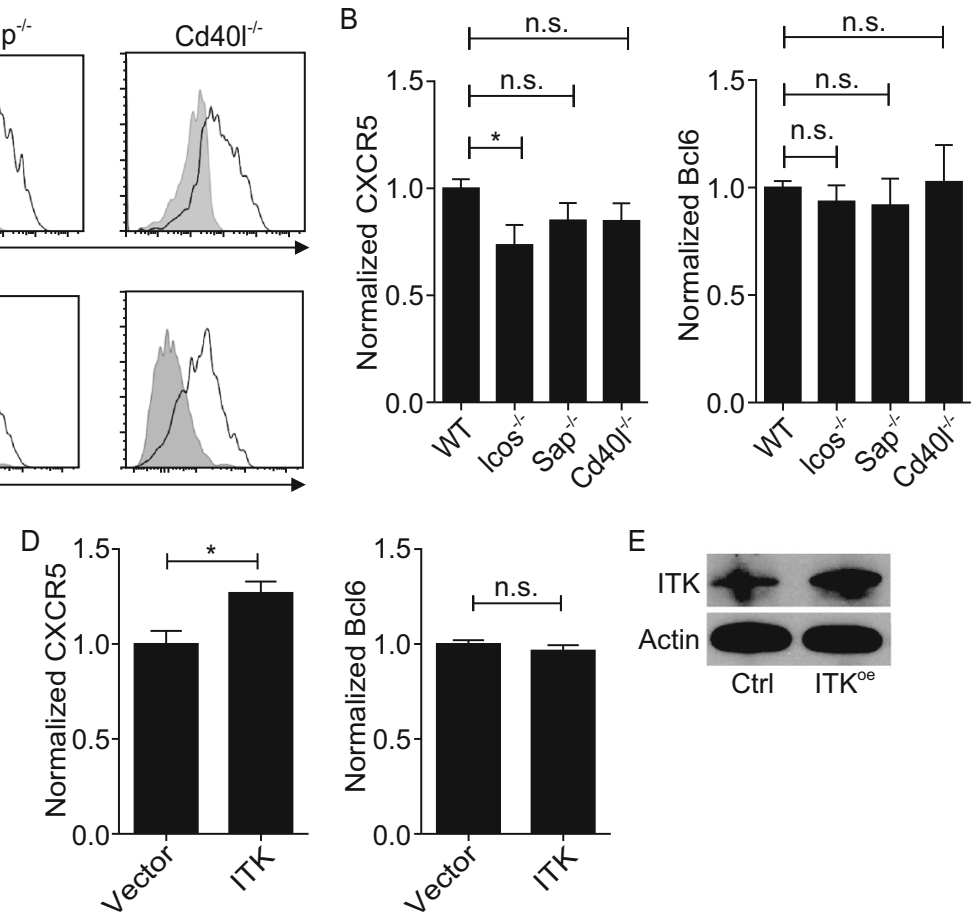

E

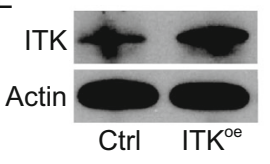

Figure 2. ICOS and ITK signaling affects CXCR5 but not Bcl6 induction. (A) Representative histograms of CXCR5 and Bcl6 expression by CMFDA-labeled OT-II T cells of indicated genotypes $24 \mathrm{~h}$ after OVA/alum/LPS immunization. Isotype staining was done with a mixture of WT, $\mathrm{ICOS}^{-/}$, Sap ${ }^{-/-}$, and $\mathrm{Cd}_{40 \mathrm{O}^{-}}$cells. (B) Normalized CXCR5 and Bcl6 expression (the mean MFI of the WT group set as 1 ), shown as mean \pm SEM of 10-13 recipient mice per group. Data are pooled from 4 independent experiments. (C and D) Representative histograms and normalized CXCR5 and Bcl6 expression (the mean MFI of the vector control group set as 1) on OT-II T cells transduced with the control or an ITK-overexpressing vector $24 \mathrm{~h}$ post immunization. (E) ITK levels in transduced cells as measured by Western blotting. Data are from two independent experiments involving 5 to 6 mice per group. ${ }^{*} P<0.05$; n.s., not significant.

upregulated CXCR5 and Bcl6 in wildtype recipients of $11-6^{-1-}$ donor BM cells under a condition of complete splenic DC replacement (Fig. S2), and reconstitution of $11-6^{-1-}$ recipients with wildtype BM cells led to somewhat improved but still significantly subdued upregulation of CXCR5 and Bcl6 on OT-II cells (Fig. 4B). These data suggest that IL-6 from radiation-resistant cells, possibly stromal cells, is essential for normal CXCR5 and Bcl6 induction on T cells, while BMderived cells are not necessary or sufficient source of IL-6.

\section{DISCUSSION}

This study reveals extremely rapid CXCR5 and Bcl6 upregulation by undivided T cells in the first $24 \mathrm{~h}$ after antigen exposure in vivo. Also using adoptive transfer of OT-II cells, Baumjohann et al. found that, at day 3.5 post immunization, Bcl6 was only upregulated in divided but not undivided T cells (Baumjohann et al., 2011). This apparent contradiction may be due to differences in anatomical locations examined or immunization routes utilized in the two studies. Interestingly, undivided OT-II cells detected at day 3.5 in our system also did not express Bcl6 (data not shown), suggesting above-mentioned factors cannot be solely responsible. Alternatively, individual $\mathrm{T}$ cells may be able to rapidly adjust CXCR5 and Bcl6 expression according to the strength of antigen stimulation and other environmental cues in the tissue, and lymphoid micro-environments in which antigen-activated T cells are located may change over time in content and distribution of such cues. Consistent with a role for environmental cues, CXCR5 is required for optimal Bcl6 upregulation in the very early phase, and CXCR5-mediated T-cell localization to the T-B border roughly coincides with the Bcl6 induction. We have further defined radiationresistant cells as an important source of IL-6 that drives early CXCR5 and Bcl6 upregulation. Because stromal cells produce other cytokines and chemokines that can influence $T$ cell functions (Malhotra et al., 2013), future studies of how stromal cells may regulate Tfh development are warranted. The fact that an apparent Tfh signature can be triggered in T cells even without cell division cautions the use of a CXCR5 ${ }^{\text {hi }} B$ cl $6^{\text {hi }}$ phenotype to automatically indicate a cell cycle-coupled, fate-commitment program as in models for Th1, Th2, and Th17 effector cell differentiation (Zhu et al., 2010). It remains possible that upregulation and maintenance of CXCR5 and Bcl6 represent a stereotypical behavior of T cells being exposed to antigen in a permissive tissue microenvironment and/or that a Tfh state can precede commitment to any effector differentiation. As cells of the Tfh 
A

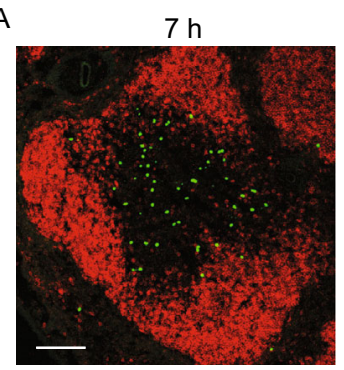

C

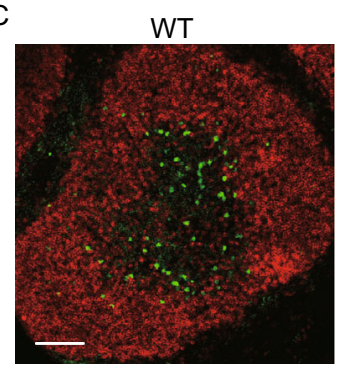

$12 \mathrm{~h}$

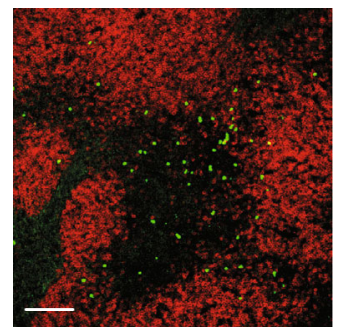

$\mathrm{Cxcr5}^{-1-}$

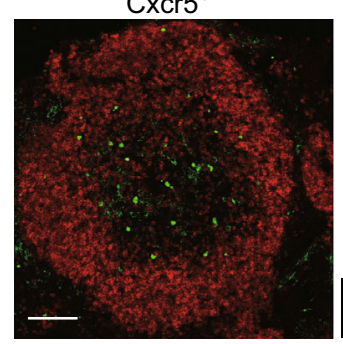

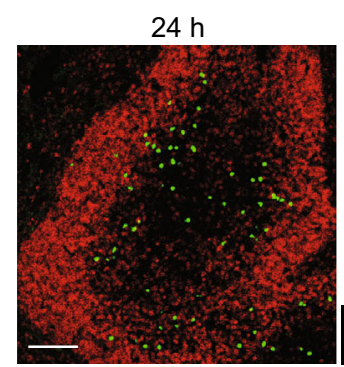

D

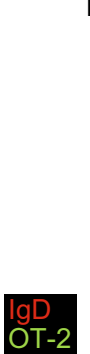

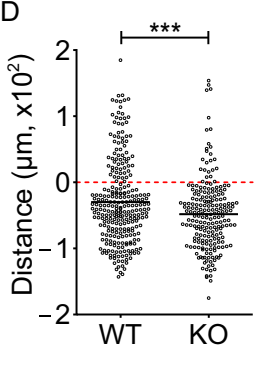

B

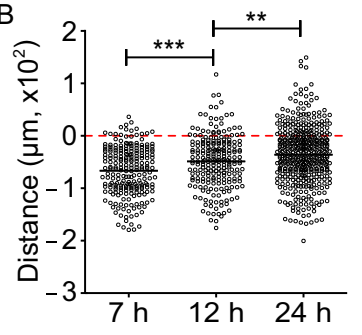

$\mathrm{E}$

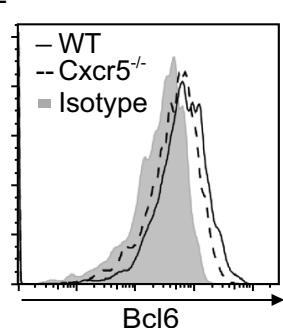

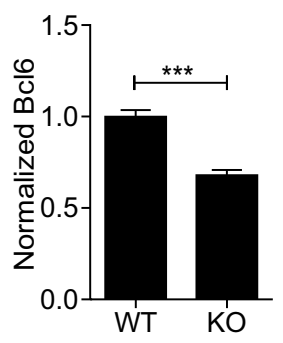

Figure 3. CXCR5 is required for early T cell relocation to the T-B border and Bcl6 upregulation. (A) Distribution patterns of OT-II T cells at indicated times after immunization. Scale bar, $100 \mu \mathrm{m}$. (B) Distances of individual cells to the T-B border, with negative and positive values indicating T-zone and follicular localization, respectively. Each symbol denotes one cell and lines denote mean values. A total of 223, 227, and 442 cells at 7, 12, $24 \mathrm{~h}$ respectively from at least 4 mice per time point were quantitated. (C) Distribution patterns of WT or Cxcr5 $5^{--}$OT-II T cells $24 \mathrm{~h}$ post immunization. A total of 273 and 210 cells from WT and Cxcr $5^{-1}$ group respectively and at least 2 mice per group were quantitated. Scale bar, $100 \mu \mathrm{m}$. (D) Distances of WT or Cxcr5 $5^{-1-}$ OT-II cells to the T-B border. (E) Representative histograms (left) and normalized Bcl6 expression (right) of WT or Cxcr5 $5^{-1-}$ OT-II T cells $24 \mathrm{~h}$ after OVA/alum/LPS immunization. Data are pooled from 3 independent experiments involving 11 mice per group. In (A) and (C), CD3 staining was omitted in the composite display for clarity. In $(E)$, isotype staining was done with cells pooled from the respective two groups. ${ }^{* \star} P<0.01$; ${ }^{* * *} P<0.001$.

phenotype are increasingly implicated in a large number of pathophysiological conditions including tumors and inflammatory diseases (Crotty 2014), the under-appreciated pattern of CXCR5 and Bcl6 expression on activated T cells as revealed in this study cautions us about assigning simple cause-effect relationship in situations involving potentially very complex interactions between Tcells and their changing tissue environment in vivo.

\section{MATERIALS AND METHODS}

Mice and bone-marrow chimeras

C57BL/6 (Jax 664), HMT (Jax 2288), Icos $^{-/-}$(Jax 4859), GFP-expressing (Jax 4353), OVA $323-339$-specific T-cell receptor transgenic OT-II (Jax 4194), Cd40/-- (Jax 2770), II-6-/- (Jax 2650), CxCr5 ${ }^{-1-}$ (Jax 6659) mice were from the Jackson Laboratory. Sap ${ }^{-1-}$ mice were a kind gift of Dr. Pamela Schwartzberg (NIH). To construct chimeras, WT or II- $6^{-1-}$ mice were irradiated $2 \times 500$ rads with an X-ray source and then reconstituted with $4 \times 10^{6} \mathrm{WT}$ or $11-6^{-/-}$bone marrow cells. Chimeras were used 8 weeks after reconstitution. All animal experiments have been conducted in accordance of governmental and institutional guidelines for animal welfare and approved by the Institutional Animal Care and Use Committee.
Adoptive cell transfer and immunization

For naïve T cell transfer, each mouse received $1 \times 10^{6}-3 \times 10^{6}$ OT-II $\mathrm{CD}^{+} \mathrm{T}$ cells isolated with the mouse $\mathrm{CD} 4^{+} \mathrm{T}$ cell isolation kit (Miltenyi Biotec) or further sorted as $\mathrm{CD} 4^{+} \mathrm{CD} 25^{-} \mathrm{CD} 62 \mathrm{~L}^{\text {high }} \mathrm{CD} 44^{\text {low }}$ cells that were stained with $1 \mu \mathrm{mol} / \mathrm{L}$ CMFDA (Invitrogen). Recipient mice were immunized one day later. When previously activated $T$ cells were used, $5 \times 10^{6}-5 \times 10^{7}$ OT-II T cells that were activated in vitro with plate-bound anti-CD3 and anti-CD28 for 4 days were injected to recipient mice 3 days prior to immunization. To immunize, $500 \mu \mathrm{g}$ OVA protein (Sigma) in alum (Thermo Scientific) together with $5 \mu \mathrm{g}$ LPS (Sigma) were intraperitoneally injected to recipient mice. For experiments involving ITK-over-expression, OT-II T cells were transduced with an MSCV-based vector that expresses GFP as a marker for cell identification by flow cytometry, as previously described (Xu et al., 2013). ITK overexpression was verified by Western blotting (anti-ITK antibody from Cell Signaling Technology).

\section{Flow cytometry}

Single-cell suspensions were blocked with $20 \mu \mathrm{g} / \mathrm{mL} 2.4 \mathrm{G} 2$ (BioXcell) for $20 \mathrm{~min}$ and then stained with indicated primary antibodies for $90 \mathrm{~min}$ and secondary reagents for $30 \mathrm{~min}$ in PBS containing $1 \%$ FBS and $5 \mathrm{mmol} / \mathrm{L}$ EDTA. Staining reagents included PE-CF594 anti-CD4, PE-Cy7 anti-CD4, APC-Cy7 anti-CD19, and DyLight649 
A

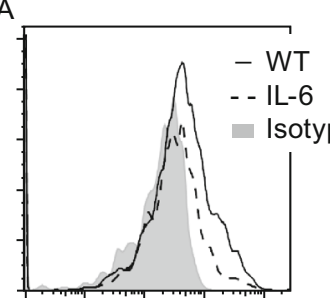

CXCR5

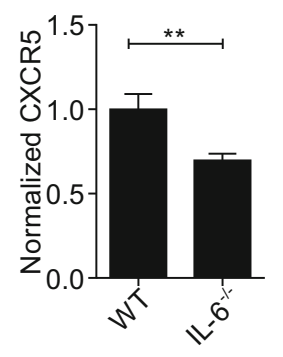

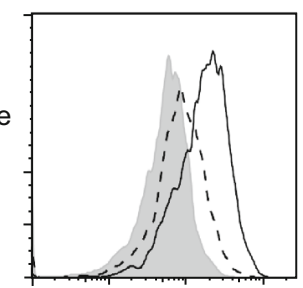

Bcl6

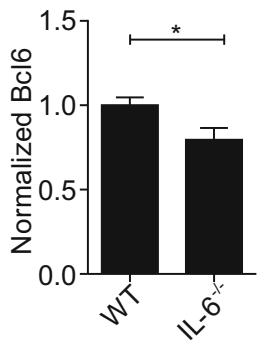

B
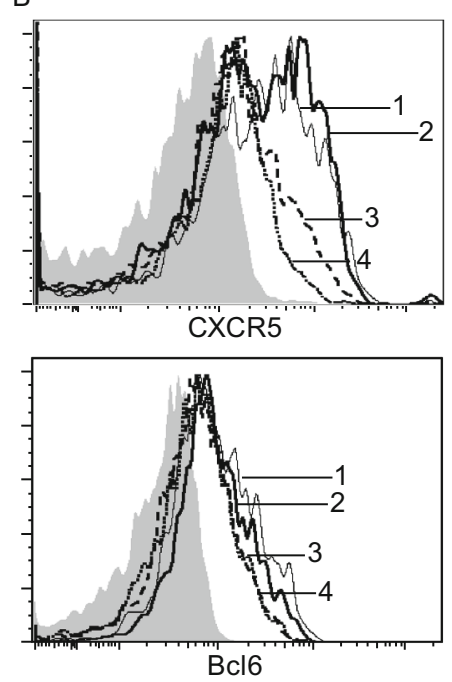

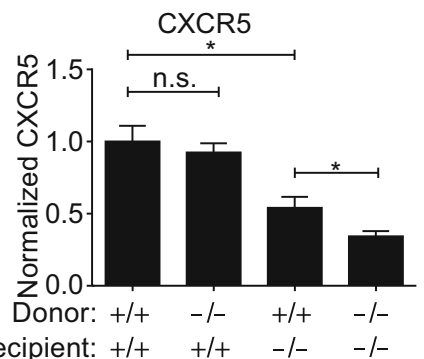

Recipient: +/+ +/+ $-/-\quad-/-$

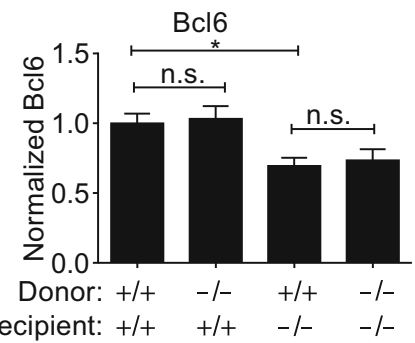

Figure 4. IL-6 from radiation-resistant cells is critical for early CXCR5 and Bcl6 upregulation. (A) Representative histograms (top) and normalized CXCR5 and Bcl6 expression (bottom) of OT-II cells one day after activation in WT or $/ 1-6^{-1-}$ recipients. Data are pooled from 2 independent experiments involving 5 or 6 mice per group. (B) Representative histograms (left) and normalized CXCR5 and Bcl6 expression (right) of OT-II cells one day after activation in chimeric hosts of indicated II-6 genotypes. 1: WT donor, WT recipient; 2: KO donor, WT recipient; 3: WT donor, KO recipient; 4: KO donor, KO recipient. Isotype control was show in gray. Cell mixture of the 4 groups was used for isotype control staining. Data are pooled from 2 independent experiments involving 5 to 9 mice per group. ${ }^{*} P<0.05 ;{ }^{*} P<0.01$; n.s., not significant.

goat anti-hamster IgG antibody from Biolegend, purified anti-PD-1 from eBioscience, AlexaFluor 647 anti-Bcl6 (K112-91), biotinylated anti-CXCR5, PE- and BV421-labeled streptavidin from BD Biosciences. Isotype control antibodies included biotinylated Rat IgG2a AlexaFluor 647 Mouse IgG1 from BD Biosciences and purified hamster IgG from eBioscience. 7-AAD from Biotium was used to exclude dead cells. To detect intracellular Bcl6, cells were stained in the Foxp3/Transcription Factor Staining Buffer Set (eBioscience) after surface staining. To accurately measure CXCR5 and Bcl6 expression, care was taken to stain the same cell samples with the respective isotype control antibodies in parallel or, for certain experiments, to use an equal-proportion mixture of cells from different treatment groups for shared isotype control staining. Data were collected on BD LSR II or Aria III cytometers and analyzed with FlowJo software (TreeStar). When data from multiple independent experiments collected on different machines were pooled, we have normalized CXCR5 or Bcl6 MFI of individual samples against the mean MFI of the corresponding control group for each experiment.

\section{Immunohistochemistry}

T-cell distribution patterns in vivo was analyzed on immunohistochemically stained splenic sections as previously described (Qi et al., 2006). Staining reagents included eFluor450 anti-CD3 (eBioscience) and AlexaFluor 647 anti-lgD (eBioscience). Sections were mounted with the ProlongGold Antifade reagent (Invitrogen) and imaged with an Olympus FV1000 microscope. To quantitatively measure positions of individual T cells in reference to the follicle, the T-B border was drawn as a line according to the CD3 staining patterns by a person blinded to sample identification, and the shortest distance from each $T$ cell to the line was recorded, with negative and positive values indicating T-zone and follicular localization, respectively.

\section{Statistical analysis}

For pairwise comparisons of endpoint means of experimental and control groups, two-tailed $t$ tests were conducted using Prism (GraphPad).

\section{ACKNOWLEDGEMENTS}

This work is funded in part by the Tsinghua-Peking Center for Life Sciences, the National Natural Science Foundation of China (Grant Nos. 81330070 and 81361120397 to H.Q.; Grant No. 31200670 to L. W.), the National Basic Research Program (973 Program) (No. 2014CB542501 to H.Q.) and the National High Technology Research and Development Program (863 Program) (No. 2012AA022403 to L.W.), and Tsinghua University Initiative Scientific Research Program (2010Z02150 to H.Q.). H.Q. is a Tsinghua-Bayer Investigator and a Tsinghua-Janssen Investigator. L.W. is partly supported by a China Postdoctoral Science Foundation grant (2013M540970) and a CLS Postdoctoral Fellowship.

\section{COMPLIANCE WITH ETHICS GUIDELINES}

Xin Chen, Weiwei Ma, Tingxin Zhang, Longyan Wu and Hai Qi declare that they have no conflict of interest.

All institutional and national guidelines for the care and use of laboratory animals were followed. 


\section{OPEN ACCESS}

This article is distributed under the terms of the Creative Commons Attribution 4.0 International License (http://creativecommons.org/ licenses/by/4.0/), which permits unrestricted use, distribution, and reproduction in any medium, provided you give appropriate credit to the original author(s) and the source, provide a link to the Creative Commons license, and indicate if changes were made.

\section{REFERENCES}

Baumjohann D, Okada T, Ansel KM (2011) Cutting edge: distinct waves of BCL6 expression during T follicular helper cell development. J Immunol 187:2089-2092

Baumjohann D, Kageyama R, Clingan JM, Morar MM, Patel S, De Kouchkovsky D, Bannard O, Bluestone JA, Matloubian M, Ansel $\mathrm{KM}$ et al (2013) The microRNA cluster miR-17 92 promotes T FH cell differentiation and represses subset-inappropriate gene expression. Nat Immunol 14:840-848

Berg LJ, Finkelstein LD, Lucas JA, Schwartzberg PL (2005) Tec family kinases in T lymphocyte development and function. Annu Rev Immunol 23:549-600

Choi Y, Kageyama R, Eto D, Escobar T, Johnston R, Monticelli L, Lao C, Crotty S (2011) ICOS receptor instructs T follicular helper cell versus effector cell differentiation via induction of the transcriptional repressor Bcl6. Immunity 34:932-946

Choi YS, Yang JA, Yusuf I, Johnston RJ, Greenbaum J, Peters B, Crotty S (2013) Bcl6 expressing follicular helper CD4 T cells are fate committed early and have the capacity to form memory. J Immunol 190:4014-4026

Crotty S (2011) Follicular helper CD4 T cells (TFH). Annu Rev Immunol 29:621-663

Crotty S (2014) T follicular helper cell differentiation, function, and roles in disease. Immunity 41:529-542

Deenick EK, Chan A, Ma CS, Gatto D, Schwartzberg PL, Brink R, Tangye SG (2010) Follicular helper T cell differentiation requires continuous antigen presentation that is independent of unique $B$ cell signaling. Immunity 33:241-253

Gigoux M, Shang J, Pak Y, Xu M, Choe J, Mak TW, Suh WK (2009) Inducible costimulator promotes helper T-cell differentiation through phosphoinositide 3-kinase. Proc Natl Acad Sci USA 106:20371-20376

Goenka R, Barnett LG, Silver JS, O'Neill PJ, Hunter CA, Cancro MP, Laufer TM (2011) Cutting edge: dendritic cell-restricted antigen presentation initiates the follicular helper $\mathrm{T}$ cell program but cannot complete ultimate effector differentiation. J Immunol 187:1091-1095

Harker JA, Lewis GM, Mack L, Zuniga El (2011) Late interleukin-6 escalates $T$ follicular helper cell responses and controls a chronic viral infection. Science 334:825-829

Hatzi K, Nance JP, Kroenke MA, Bothwell M, Haddad EK, Melnick A, Crotty S (2015) BCL6 orchestrates Tfh cell differentiation via multiple distinct mechanisms. J Exp Med 212:539-553

Johnston RJ, Poholek AC, DiToro D, Yusuf I, Eto D, Barnett B, Dent AL, Craft J, Crotty S (2009) Bcl6 and Blimp-1 are reciprocal and antagonistic regulators of $\mathrm{T}$ follicular helper cell differentiation. Science 325:1006-1010
Kang SG, Liu WH, Lu P, Jin HY, Lim HW, Shepherd J, Fremgen D, Verdin E, Oldstone MBA, Qi H et al (2013) MicroRNAs of the miR17 92 family are critical regulators of $\mathrm{T} \mathrm{FH}$ differentiation. Nat Immunol 14:849-857

Kerfoot SM, Yaari G, Patel JR, Johnson KL, Gonzalez DG, Kleinstein SH, Haberman AM (2011) Germinal center B cell and $\mathrm{T}$ follicular helper cell development initiates in the interfollicular zone. Immunity 34:947-960

Kitano M, Moriyama S, Ando Y, Hikida M, Mori Y, Kurosaki T, Okada $\mathrm{T}$ (2011) Bcl6 protein expression shapes pre-germinal center B cell dynamics and follicular helper T cell heterogeneity. Immunity 34:961-972

Liu X, Yan X, Zhong B, Nurieva RI, Wang A, Wang X, Martin-Orozco $\mathrm{N}$, Wang Y, Chang SH, Esplugues E et al (2012) Bcl6 expression specifies the $\mathrm{T}$ follicular helper cell program in vivo. J Exp Med 209:1841-1852

Liu X, Chen X, Zhong B, Wang A, Wang X, Chu F, Nurieva RI, Yan X, Chen P, van der Flier LG et al (2014) Transcription factor achaete-scute homologue 2 initiates follicular T-helper-cell development. Nature 507:513-518

Ma CS, Suryani S, Avery DT, Chan A, Nanan R, Santner-Nanan B, Deenick EK, Tangye SG (2009) Early commitment of nave human CD4+ T cells to the $T$ follicular helper $(F H)$ cell lineage is induced by IL-12. Immunol Cell Biol 87:590-600

Malhotra D, Fletcher AL, Turley SJ (2013) Stromal and hematopoietic cells in secondary lymphoid organs: partners in immunity. Immunol Rev 251:160-176

Nakayamada S, Kanno Y, Takahashi H, Jankovic D, Lu K, Johnson T, Sun HW, Vahedi G, Hakim O, Handon R et al (2011) Early Th1 cell differentiation is marked by a Tfh cell-like transition. Immunity 35:919-931

Nurieva RI, Chuvpilo S, Wieder ED, Elkon KB, Locksley R, Serfling E, Dong C (2007) A costimulation-initiated signaling pathway regulates NFATc1 transcription in T lymphocytes. J Immunol 179:1096-1103

Nurieva RI, Chung Y, Hwang D, Yang XO, Kang HS, Ma L, Wang YH, Watowich SS, Jetten AM, Tian Q et al (2008) Generation of T follicular helper cells is mediated by interleukin-21 but independent of $\mathrm{T}$ helper 1, 2, or 17 cell lineages. Immunity 29:138-149

Nurieva RI, Chung Y, Martinez GJ, Yang XO, Tanaka S, Matskevitch TD, Wang YH, Dong C (2009) Bcl6 mediates the development of T follicular helper cells. Science 325:1001-1005

Parry RV, Rumbley CA, Vandenberghe LH, June CH, Riley JL (2003) CD28 and inducible costimulatory protein Src homology 2 binding domains show distinct regulation of phosphatidylinositol 3-kinase, Bcl-xL, and IL-2 expression in primary human CD4 T lymphocytes. J Immunol 171:166-174

Qi H, Egen JG, Huang AYC, Germain RN (2006) Extrafollicular activation of lymph node $B$ cells by antigen-bearing dendritic cells. Science 312:1672-1676

Qi H, Liu D, Ma W, Wang Y, Yan H (2014) Bcl-6 controlled TFH polarization and memory: the known unknowns. Curr Opin Immunol 28:34-41

Schmitt N, Morita R, Bourdery L, Bentebibel SE, Zurawski SM, Banchereau J, Ueno H (2009) Human dendritic cells induce the differentiation of interleukin-21-producing $\mathrm{T}$ follicular helper-like cells through interleukin-12. Immunity 31:158-169 
Ueno H, Banchereau J, Vinuesa CG (2015) Pathophysiology of T follicular helper cells in humans and mice. Nat Immunol 16:142152

Vinuesa C, Cyster J (2011) How T cells earn the follicular rite of passage. Immunity 35:671-680

Wu Y, El Shikh MEM, El Sayed RM, Best AM, Szakal AK, Tew JG (2009) IL-6 produced by immune complex-activated follicular dendritic cells promotes germinal center reactions, IgG responses and somatic hypermutation. Int Immunol 21:745-756
Xu H, Li X, Liu D, Li J, Zhang X, Chen X, Hou S, Peng L, Xu C, Liu W et al (2013) Follicular T-helper cell recruitment governed by bystander B cells and ICOS-driven motility. Nature 496:523-527

Yu D, Rao S, Tsai LM, Lee SK, He Y, Sutcliffe EL, Srivastava M, Linterman M, Zheng L, Simpson N et al (2009) The transcriptional repressor Bcl-6 directs $\mathrm{T}$ follicular helper cell lineage commitment. Immunity 31:457-468

Zhu J, Yamane H, Paul WE (2010) Differentiation of effector CD4 T cell populations. Annu Rev Immunol 28:445-489 